\title{
Diagnostic Efficacy of Bronchoalveolar Lavage in a Rural Industrial Hospital in Madhya Pradesh, India
}

\author{
Alka Upreti1 ${ }^{1}$ Kumari Pratima ${ }^{2}$ \\ 1 Department of Pathology, HIMS, Ataria, Sitapur, Uttar Pradesh, India. \\ ${ }^{2}$ Department of ENT, Nehru Shatabdi Chikitsalaya Hospital, Singrauli, Madhya Pradesh, India
}

ABSTRACT

\section{BACKGROUND}

The incidence of lung carcinomas is on rise and it is the second most common cause of death due to carcinomas in the West. Due to rise in air pollutants other lung diseases are also on rise. The use of cytological methods in the diagnosis of pathological lesions of respiratory tract has been generally acclaimed as one of its most successful application. Flexible fibre optic bronchoscope revolutionised respiratory cytology because techniques like broncho alveolar lavage, brush cytology, bronchial biopsy, and fine needle aspiration cytology (FNAC) have become easier and more acceptable, shifting the emphasis from advanced inoperable malignancy to use of cytology as first line diagnostic and management tool. Broncho alveolar lavage (BAL) which was originally developed as a therapeutic tool for pulmonary alveolar proteinosis, cystic fibrosis and intractable asthma also has gained acceptance and steady popularity as a tool for diagnosis of lung pathology. We wanted to analyse BAL examined in the Department of Pathology, Nehru Shatabdi Chikitsalaya (NSC), NCL and establish its utility as a diagnostic tool in our setup and reduce referral to higher centres.

\section{METHODS}

36 BAL samples were examined from August 2006 to December 2007. Bronchoscopy was performed by ENT specialists among all patients who were not relieved by the medical treatment and their X-ray lung showed some findings, as an outdoor procedure. Patients were asked to come in an empty stomach, and X-ray chest was done before bronchoscopy. All bronchoscopies were performed under local anaesthesia (LA) except for a 2 yrs. old child. BAL fluid was subjected to cytological studies and Ziehl-Neelsen staining wherever required.

\section{RESULTS}

Out of 36 cases, nonspecific inflammation was seen in 13 cases, tuberculosis in 8 cases, where in three samples of sputum were negative for acid-fast bacillus (AFB) and BAL showed bacteria in many fields. Two cases were found to have aspergillosis, to rule out contamination, serum antibodies against aspergillosis were estimated which was very high ruling out contamination. Out of 8 cases of malignancy one was metastasis from mature teratoma testis. Two cases of adenocarcinoma (both females) and two cases of squamous cell carcinoma were found, in one case of adenocarcinoma and two cases of squamous cell carcinoma (SCC), BAL was found negative. No history was available regarding tobacco smoking in females with adenocarcinoma.

\section{CONCLUSIONS}

Study of BAL obtained by simple non-invasive technique has improved the diagnostic accuracy of lung diseases. Carcinomas can be diagnosed at an early operable stage. The combination of BAL with brush cytology increases the accuracy. To conclude, in all bronchoscopic examination BAL should be performed and should be subjected to microscopic examination irrespective of the age of patient.

\section{KEY WORDS}

Fiberoptic Bronchoscope, Lung, BAL, Tuberculosis, Adenocarcinoma Lung, SCC Lung
Corresponding Author:

Dr. Alka Upreti,

H. No. 8/3, 10 Indira Nagar,

Lucknow-226016,

Uttar Pradesh, India.

E-mail:alkaupreti@gmail.com

DOI: $10.14260 / \mathrm{jemds} / 2021 / 459$

Financial or Other Competing Interests: None.

How to Cite This Article:

Upreti A, Pratima K. Diagnostic efficacy of bronchoalveolar lavage in a rural industrial hospital in Madhya Pradesh, India. J. Evolution Med. Dent. Sci. 2021;10(30):2244-2248, $10.14260 /$ jemds $/ 2021 / 459$

Submission 05-03-2021, Peer Review 24-05-2021, Acceptance 31-05-2021, Published 26-07-2021. 


\section{BACKGROUND}

Lung malignancies are one of the leading causes of cancer related deaths in men and women. Bronchial irrigation with saline solution via a catheter passed through a rigid bronchoscope was first reported in 1927 and the term bronchial lavage was given by Stitt in $1932 .{ }^{1}$ The use of cytological methods in the diagnosis of pathological lesions of respiratory tract has been generally acclaimed as a safe, well tolerated one and most successful application. BAL which was originally developed as a therapeutic tool for pulmonary alveolar proteinosis, cystic fibrosis and intractable asthma, it also gained acceptance and steady popularity as a tool for diagnosis of lung pathology inflammatory as well as malignancy. Flexible fibre optic bronchoscope revolutionised respiratory cytology because techniques like Broncho alveolar lavage, brush cytology, bronchial biopsy and fine needle aspiration cytology have become easier and more acceptable, shifting the emphasis from advanced inoperable malignancy to use of cytology as first line diagnostic and management tool.

Lung is the organ which is always in contact with surrounding atmosphere and its contaminants. We breathe litres of air and there are chances that some organism may start growing in it and is more liable in coal mines workers. Due to limitation of $\mathrm{x}$-rays, many of pathological lesions cannot be seen on plain chest x-rays. Moreover, in many cases inflammatory and neoplastic pathology cannot be differentiated.

We wanted to analyse BAL examined in the Department of Pathology, Nehru Shatabdi Chikitsalaya (NSC), NCL and establish its utility as a diagnostic tool in our setup and reduce referral to higher centres.

\section{METHODS}

This is a retrospective study done in a 300-bed secondary care hospital developed for the treatment of coal field's workers and surrounding population, situated in a small town of Madhya Pradesh, Singrauli. All cases were followed up properly. The nearest town with facilities of computed tomography (CT) and magnetic resonance imaging (MRI) was situated approx. $300 \mathrm{Kms}$.

36 BAL samples were examined from August 2006 to December 2007. Sample size was taken based on the convenience of the study. Bronchoscopy was performed by ENT specialists as an outdoor procedure, in all patients who were not relieved by medical treatment or X-ray lung showed some findings. Patients were asked to come in an empty stomach, X-ray chest was done before bronchoscopy. All bronchoscopies were performed under LA except in one $2 \mathrm{yr}$. old child. $10 \%$ lignocaine was sprayed in throat.

Xylocaine jelly was applied in the nostril and at the top of bronchoscope. At the level of vocal cord $2 \%$ xylocaine was pushed through the working channel. Colour of mucosa, carina, mucosal rugosities, mobility of mucosa and any abnormal nodule or growth were the things observed. Lavage was performed from the affected lobe of the lung. For this fibre optic bronchoscope was fixed at the orifice of lobar or segmental bronchus.
$20 \mathrm{ml}$ of normal saline was pushed, waited for one minute, suction was performed, and fluid collected in the trap. The fluid was sent to the laboratory within half an hour along with a proforma containing details of clinical history provisional diagnosis and radiological findings of the patient. Fluid was immediately processed for examination. One part was centrifuged at slow speed $(250 \mathrm{~g})$ for 10 minutes for cytological study and another part was centrifuged at high speed (1500 RPM) for 5 minutes for microbiological examination. Slides were prepared. No any available material was wasted.

Slides for examination were alcohol fixed and air dried. The air-dried smears were stained with May-Grunwald Giemsa stain and Ziehl-Neelsen stain and alcohol fixed with PAP stain. Slides were then examined under microscope. All the cases were followed up, cases diagnosed as malignant lesions were referred to a tertiary care centre and cases diagnosed as inflammatory lesions were given specific treatment at our setup. The study was approved by ethics committee and informed consent was obtained.

\section{Statistical Analysis}

The Statistical Package for Social Science \{SPSS version 20 was used for data analysis. Mean, median, and standard deviation (SD) were used to describe quantitative data. Qualitative data were summarised using frequency and percentages.

\section{RESULTS}

In our study of 36 cases most of the cases were above 20 yrs. (78 \%) and only $22 \%$ (8 cases) were below 20 years as shown in Table 1. All samples were subjected to Ziehl-Neelsen stain along with May-Grunwald stain and PAP stain. It was observed that out of 36 cases, inflammatory pathology was the most common finding (23 cases). Nonspecific inflammation (13 cases), eight cases of tuberculosis were diagnosed on the basis of presence of $\mathrm{AFB}$, though all of them were AFB negative in three consecutive samples of sputum. Tuberculosis was observed mostly above 20 yrs. (7 cases). Two cases of fungal pathology with mycelia of aspergillosis in BAL were found. All cases of tuberculosis and nonspecific inflammation were followed up and follow up X-ray chest showed resolution of pathology. In cases of fungal pathology to rule out contamination, serum antibodies were estimated by sending sample to a referral lab and in both cases antibody titre was very high which ruled out contamination. Table II

\begin{tabular}{|ccc|}
\hline Sl. No. & Age Group & No. of Cases \\
1 & $0-5$ yrs. & 1 \\
2 & $5-10$ yrs. & 1 \\
3 & $10-20$ yrs. & 06 \\
4 & $20-40$ yrs. & 14 \\
5 & $40-60$ yrs. & 07 \\
6 & 60 yrs. and above & 07 \\
\hline \multicolumn{3}{|c}{ Table I. Age Wise Distribution of Cases } \\
\hline
\end{tabular}

Both the cases of aspergillosis were above $60 \mathrm{yrs}$. and were immunocompromised. In malignancy group, only one young boy of 18 years was found positive for malignancy showing benign group of cells in adenomatous arrangement. He had four round opacities in Rt lung, because he was a young boy, 
his testes were examined and on ultrasound $2 \mathrm{~cm}$ mass was found in Rt testis, fine needle aspiration cytology (FNAC) of which revealed non seminomatous germ cell tumour. The final histological diagnosis was mature teratoma.

\begin{tabular}{|ccccc|}
\hline Sl. No. & Age Group & $\begin{array}{c}\text { Nonspecific } \\
\text { Inflammation }\end{array}$ & Tuberculosis & Fungal \\
1 & $0-5$ yrs. & 1 & & \\
2 & $5-10$ yrs. & 1 & 1 & \\
3 & $10-20$ yrs. & 2 & 5 & \\
4 & $20-40$ yrs. & 7 & 1 & 02 \\
5 & $40-60$ yrs. & 1 & 1 & $\mathbf{0 8}$ \\
6 & 60 yrs. and above & 1 & $\mathbf{1 3}$ & $\mathbf{0 2}$ \\
Total & Table II. Age Wise Distribution of Inflammatory Lesions \\
\hline \multicolumn{5}{c}{} \\
\hline
\end{tabular}

\begin{tabular}{|ccccc|}
\hline Sl. No. & Age Group & Male & Female & Histopathological Diagnosis \\
1 & $0-40$ yrs. & 1 & & Metastatic mature teratoma testis \\
2 & $40-50$ yrs. & - & - & \\
3 & $50-55$ yrs. & - & 02 & Broncho adenocarcinoma (BAC) \\
4 & $55-60$ yrs. & - & 02 & Broncho adenocarcinoma (BAC) \\
5 & $60-65$ yrs. & 2 & - & Squamous cell carcinoma \\
6 & $65-70$ yrs. & 2 & 1 & Squamous cell carcinoma \\
7 & $70-75$ yrs. & 02 & - & Squamous cell carcinoma \\
8 & 75 yrs. and above & 1 & - & Squamous cell carcinoma \\
Total & & $\mathbf{0 8}$ & $\mathbf{0 5}$ & \\
\hline \multicolumn{4}{|c|}{ Table III. Age $\&$ Sex Wise Distribution of Malignant Lesions } \\
\hline
\end{tabular}

\begin{tabular}{|cccc|}
\hline $\begin{array}{c}\text { Sl. } \\
\text { No. }\end{array}$ & $\begin{array}{c}\text { No. of } \\
\text { Cases }\end{array}$ & $\begin{array}{c}\text { Cytological } \\
\text { Diagnosis }\end{array}$ & $\begin{array}{c}\text { Histopathological } \\
\text { Diagnosis }\end{array}$ \\
1 & 1 & Metastatic deposits of NSGCT & $\begin{array}{c}\text { Mature teratoma with lung } \\
\text { metastasis }\end{array}$ \\
2 & 3 & Adenocarcinoma BAC & BAC \\
4 & 1 & Normal cytology & BAC \\
5 & 6 & $\begin{array}{c}\text { Well differentiated squamous } \\
\text { cell carcinoma }\end{array}$ & $\begin{array}{c}\text { Well differentiated squamous cell } \\
\text { carcinoma }\end{array}$ \\
5 & 2 & Normal & $\begin{array}{c}\text { Well differentiated squamous cell } \\
\text { carcinoma }\end{array}$ \\
Total & $\mathbf{1 3}$ & & \\
\hline Table IV. Cytological Diagnosis with Histopathological Correlation \\
\hline \multicolumn{5}{c}{} \\
\hline \multicolumn{4}{c}{} \\
\hline
\end{tabular}

All the other cases of malignancy were above $50 \mathrm{yrs}$. of age. Out of thirteen cases of malignancy, females were less than males, 5:8 cases, and were found to be having BAC at an early age of 50 - 60 yrs. Squamous cell carcinoma (SCC) was found in older age group of $65 \mathrm{yrs}$. and above. History of cigarette / bidi smoking was present in all cases of SCC. Table III

Smears with clean background, 3-dimensional clusters, flat sheets, papillae, orderly arrangement of cells with round uniform nuclei, predominance of mucinous cells, overlapping nuclei, irregular nuclear membranes, fine granular chromatin, macro nucleoli, intranuclear cytoplasmic inclusions, and nuclear grooves were diagnosed as bronchoalveolar carcinoma. $^{2}$ Out of four cases of bronchoalveolar carcinoma one was found false negative, may be because it was a case of typical BAC which showed cytological features including clean background, absence of 3-dimensional clusters, neoplastic cells in flat sheets, orderly arrangement of cells with round uniform nuclei, absence of nuclear overlap, absence of irregular nuclear membranes, fine granular chromatin, and nuclear grooves. ${ }^{3}$

Smears with an abundant granular debris, necrosis and abundant dyscohesive cells, that may be polygonal, rounded or elongated, dense cytoplasmic orangeophilia in Papanicolaou stain, pleomorphic hyperchromatic and often pyknotic nuclei, obscured nucleoli and chromatin detail, Tadpole or fibre-like cells, frequent anucleate cells twisted keratin strands (Herxheimer spirals) were diagnosed as cases of squamous cell carcinoma.

Tadpole or fibre-like cells are bizarre, elongated, spindleshaped cells which can often be seen.
The cells of moderately or poorly differentiated tumours show larger nuclei with coarse and granular chromatin texture and cyanophilic cytoplasm (with Papanicolaou stains); they are often arranged in thick groups. Keratinisation is rare or absent.

Out of eight cases of squamous cell carcinoma two were found false negative. As the patients were not improving with medical treatment, they were referred to higher centre stand on follow-up it was observed that our cytological diagnosis was wrong. Table IV.

\section{DISCUSSION}

Flexible fibre optic bronchoscope has become very useful tool in patient care and medical research since its introduction in 1968 by Ikeda et al. Proper selection of patient is necessary to ensure effective and safe procedure. Role for flexible bronchoscope with collection of BAL and its study has provided increased scope in research on repiratory tract pathology.

The significant clinical presentations, and x-ray findings in many cases of tuberculosis in our study with sputum negative smears for AFB, though suggest that the signs and symptoms, and radiographic findings are suggestive of pulmonary tuberculosis, but cannot confirm the diagnosis of pulmonary tuberculosis. Therefore, patients with radiographic and clinical findings compatible with Pulmonary Tuberculosis ( PTB) but negative for sputum smear are a challenge to the physician to start with Anti-tubercular treatment (ATT). It has been reported that $74 \%$ of these patients develop active tuberculosis in five years if not treated. ${ }^{4}$ Flexible fibre optic bronchoscopy is considered as a safe diagnostic and interventional tool, even in young or extremely premature infants. ${ }^{5}$ Caminero et al. concluded that bronchoscopy should be conducted on all patients without expectoration and negative sputum bacilloscopy and that BAL collection should be a routine procedure as it was simple and usually uncomplicated technique. ${ }^{6}$

Wallace et al. as well as Kennedy et al and Vijayan et al. ${ }^{5 \& 8}$ have demonstrated lower yield whereas Baughman et al. reported $87 \%$ of bronchoscopy sample positivity in sputum smear negative cases. ${ }^{9}$ A study by Mohan et al. ${ }^{10}$ confirmed PTB in 22 of the 50 patients from BAL. BAL had significant sensitivity and specificity in a study by Conde et al. and was useful in diagnosis of PTB in $72 \%$ cases. ${ }^{11}$ In our study, the sensitivity was $34.7 \%$ little lesser than the study by Mohan et al. and Conde et al. Small sample size of our study could be the reason for it. Mustaq Ahmad etal.12 detected 61 / 190 (32.1\%) cases of pulmonary tuberculosis who were sputum negative which was lower than the findings of our study. Thus BAL is considered best for diagnosis of TB. ${ }^{7}$

In our study, malignant patients had slight male dominance with male to female ratio of $1.6: 1$, which was very much lower compared to other studies by Reddy AS et al. (2.64:1), Bhat $N$ et al. (6.3:1), Sareen R et al. (8.4:1).13,14,15 but was little more in comparison to study of Shubhra T et al. ${ }^{16}$ (1.29:1). The mean age of the malignancy was 57.57 years with commonest age group of $5^{\text {th }}$ decade which was higher in our study as we found most of the cases in 6th decade of life.

We found one case of metastatic carcinoma out of 13 cases of malignancy. Shubhra et al. also found on case of metastatic 
carcinoma out of 23 cases of malignancies. Our case of metastatic carcinoma was a young male with metastasis of mature teratoma testis. About $1 / 3^{\text {rd }}$ cases of pure testicular teratomas present with advance disease.

Our study showed, squamous cell carcinoma (61.5\%) was the commonest type of carcinoma of lung followed by adenocarcinoma $(17.40 \%)$ of lung which was similar to the results by Shubhra el al. ${ }^{16}$ and Kotadia TP et al. ${ }^{17}$ Whereas studies by Reddy AS et al. showed adenocarcinomas as the most common malignancy and Bhat $\mathrm{N}$ et al. showed small cell carcinoma as the second most common malignancy. ${ }^{13,14}$ Table V.

\begin{tabular}{|c|c|c|c|c|c|}
\hline Studies & $\begin{array}{l}\text { Squamous } \\
\text { Cell } \\
\text { Carcinoma }\end{array}$ & $\begin{array}{c}\text { Adeno- } \\
\text { Carcinoma }\end{array}$ & $\begin{array}{l}\text { Small Cell } \\
\text { Carcinoma }\end{array}$ & $\begin{array}{c}\text { Metastatic } \\
\text { Deposits }\end{array}$ & ${ }^{c}$ Others \\
\hline $\begin{array}{l}\text { Kotadia TP } \\
\text { el al. }\end{array}$ & $39.43 \%$ & $21.21 \%$ & $13.63 \%$ & - & $16.65 \%$ \\
\hline Bhat $\mathrm{N}$ et al. & $68.55 \%$ & $4.93 \%$ & $23.02 \%$ & - & $4.23 \%$ \\
\hline Reddy AS et al. & $31.02 \%$ & $34.82 \%$ & $6.91 \%$ & - & $27.09 \%$ \\
\hline Gaur DS et al. & $29.6 \%$ & $12.7 \%$ & $21.13 \%$ & - & $36.62 \%$ \\
\hline Shubhra et al. & $65.21 \%$ & $17.40 \%$ & $13.04 \%$ & $4.34 \%$ & - \\
\hline Present study & $61.5 \%$ & $30.76 \%$ & - & $7.69 \%$ & \\
\hline
\end{tabular}

\begin{tabular}{|lccccc|}
\hline $\begin{array}{c}\text { Sareen R } \\
\text { et al. }\end{array}$ & $\begin{array}{c}\text { Bhat N } \\
\text { et al. }\end{array}$ & $\begin{array}{c}\text { Gaur DS } \\
\text { et al. }\end{array}$ & $\begin{array}{c}\text { Shubhra } \\
\text { et al. }\end{array}$ & $\begin{array}{c}\text { Present } \\
\text { Study }\end{array}$ \\
\hline Sensitivity & $72.69 \%$ & $35.5 \%$ & $39.40 \%$ & $47.83 \%$ & $76.9 \%$ \\
\hline \multicolumn{4}{|l}{ Table VI. Sensitivity of BAL in Various Studies of Malignancies } \\
\hline
\end{tabular}

In our study, the sensitivity, was $76.9 \%$. Shubhra et al. ${ }^{16}$ Gaur DS et al. reported sensitivity of $47.8 \%$ and $39.40 \%$ respectively, while Sareen R et al. reported a sensitivity as high as $72.69 \%$ for BAL. ${ }^{15}$ Higher sensitivity in our study may be because we have not wasted any material and examined all slides thoroughly. Table VI.

\section{CONCLUSIONS}

Due to good yield of cytological material directly collected from respiratory tract by means of BAL, or brush cytology, bronchial biopsy and trans bronchial FNA directly from the lesion, the examination of sputum for malignant cells became obsolete.

Cytological material is better obtained by brush cytology as in BAL exfoliated cells are collected. Exfoliation is poor in well differentiated carcinomas and more with poorly differentiated ones. The exfoliated cells start degeneration and we may get degenerated cells which makes it difficult to differentiate malignant cells from non-malignant cells.

For inflammatory lesions BAL is richer in causative organism and inflammatory cells. Therefore, study of BAL is very useful for inflammatory pathology as we can also subject the available material for bacterial or fungal culture as per requirement and can also can be subjected to gene expert. Multidrug-resistant (MDR) tuberculosis with culture and sensitivity can be diagnosed.

For diagnosis of malignancies, if BAL brush cytology and FNAC is done it might increase the accuracy.

Study of BAL obtained by simple non-invasive technique has improved diagnostic accuracy of lung diseases. Sputum negative samples can be subjected to GeneXpert along with Zeil Neelsen stain and demonstration of AFB. Carcinomas can be diagnosed at an early operable stage.
In a secondary care hospital if we can rule out malignancy in a major group of cases, it decreases load on higher centres and also avoids inconvenience to patients as major group of patients will get treatment in their local hospital and only few patients require treatment at higher centre that too with proper diagnosis.

To conclude all bronchoscopic examination, BAL should be performed and should be subjected to microscopic examination irrespective of the age of patient.

Data sharing statement provided by the authors is available with the full text of this article at jemds.com.

Financial or other competing interests: None.

Disclosure forms provided by the authors are available with the full text of this article at jemds.com.

\section{REFERENCES}

[1] Meyers KC, Raghu G, Baughman RP, et al. An official American Thoracic Society cliniclal practice guideline: the clinical utility of broncheoalveolar lavage cellular analysis in interstitial lung disease. Am J Res Crit care Med 2012:185(9):1004-14.

[2] Roger V, Nasiell M, Linden M, et al. Cytologic differential diagnosis of bronchiolo-alveolar carcinoma and bronchogenic adenocarcinoma. Acta Cytol 1976;20(4):303-7.

[3] Morishita Y, Fukasawa M, Takeuchi M, et al. Small-sized adenocarcinoma of the lung. Cytologic characteristics and clinical behaviour. Cancer 2001;93(2):124-31.

[4] Hong King Chest Service/ Tuberculosis Research Centre, Madras/ British Medical Research Council. A controlled trial of 2-months, 3-months and 12-months regimens of chemotherapy for sputum-smear-negative pulmonary tuberculosis: results at 60 months. Am Rev Respir Dis 1984;130(1):23-8.

[5] Nussbaum E. Pediatric fiberoptic bronchoscopy: clinical experience with 2,836 bronchoscopies. Pediatr Crit Care Med 2002;3(2):171-6.

[6] Luna CJA, de Castro RF, Campos-Herrero I, et al. The efficacy of bronchoalveolar lavage in the diagnosis of pulmonary tuberculosis. Arch Bronconeumol 1994;30(5):236-9.

[7] Venkateshiah SB, Mehta AC. Role of flexible brochoscopy in the diagnosis of pulmonary tuberculosis in immunocompetent individuals. J Bronchol 2003;10:3006.

[8] Vijayan VK. Role of BAL in the diagnosis and immunological evaluation of patients with pulmonary tuberculosis. Indian J Tuberculosis 2000;47:73-8.

[9] Baughman RP, Dohn MN, Loudon RG, et al. Bronchoscopy with bronchoalveolar lavage in tuberculosis and fungal infections. Chest 1991;99(1):92-7.

[10] Mohan A, Pande JN, Sharma SK, et al. Bronchoalveolar lavage in pulmonary tuberculosis: a decision analysis approach. Q J Med: An Int J Med 1995;88(4):269-76.

[11] Conde MB, Soares SL, Mello FC, et al. Comparison of sputum induction with fiberoptic bronchoscopy in the diagnosis of tuberculosis: experience at an Acquired Immune Deficiency Syndrome Reference Center in Rio De 
Janeiro, Brazil. Am J Respir Crit Care Med 2000;162(6):2238-40.

[12] Mustaq A, Ibrahim WH, Al Sarafandi S, et al. Diagnostic value of bronchoalveolar Lavage in the subset of patients with negative sputum/smear and microbacterial culture and suspicion of pulmonary tuberculosis. Int J Infect Dis 2019;82:96-101.

[13] Reddy SA, Vivekanand N, Durga K. Efficacy of bronchial wash and brush cytology in the diagnosis of lung cancers. Sch J App Med Sci 2014;2(2D):816-20.

[14] Bhat N, Nazeir MJ, Bashir H, et al. Correlation of bronchial biopsy with bronchoalveolar lavage in lung malignancies. Inter J Res Med Sci 2016;4(2):428-35.
[15] Sareen R, Pandey CL. Lung malignancy: diagnostic accuracies of bronchoalveolar lavage, bronchial brushing and fine needle aspiration cytology. Lung India 2016;33(6):635-41.

[16] Shubhra T, Chandrashekhar PB. Diagnostic efficacy of bronchoalveolar lavage (BAL) in lung malignancies. Int J Res Med Sci 2018;6(9):2983-9.

[17] Kotadia TP, Jasani JH, Vekaria PN. Comparison of bronchial biopsy, bronchoalveolar lavage (BAL), brush cytology and imprint cytology in suspected cases of lung cancer. Int J Biomedical and Advance Research 2013;4(9):1. 